\title{
Should Governments Compete for Foreign Direct Investment?*
}

\author{
Barbara G. Katz \\ Stern School of Business, NYU \\ ESSEC Business School \\ bkatz@stern.nyu.edu \\ Joel Owen \\ Stern School of Business, NYU \\ ESSEC Business School \\ jowen@stern.nyu.edu
}

April 2003 


\begin{abstract}
We study two governments, each considering whether or not to compete to attract a foreign monopoly firm into its own domestic market. The competition, should it occur, would involve offering incentives to the firm. The incentives, which are costly for the governments to provide, lower the firm's marginal cost of production. Faced with the offers from each country, the firm must choose one of four options: to enter either of the markets, produce there and export to the other, to enter both markets simultaneously with only local production, or to reject all offers. We find conditions under which it would be optimal for one of the two countries not to compete with the other, preferring instead to import the commodity from the country that attracted the firm, rather than incurring the additional costs that would have been necessary to make its own economy more attractive to the foreign firm. We show that when importing the good is a possibility, there are conditions under which, knowing that it will lose (win) the competition for the firm, the country nonetheless finds it optimal to (not) compete. Also, we derive the market structure by establishing the relationship between the option chosen by the firm and the characteristics of the two governments trying to attract the firm.
\end{abstract}

JEL Classifications: F21, F23, L1 


\section{Should Governments Compete for Foreign Direct Investment?*}

\section{Introduction}

In this paper we model the decision processes of two countries that are considering whether or not to compete to attract a foreign firm to produce in their respective domestic markets. We provide some answers to such questions as: Under what conditions should a country compete with another for foreign direct investment (FDI) rather than simply import? If a country knows that it will lose the competition for FDI, are there conditions under which it should still compete? If a country knows that it will win the competition for FDI, are there conditions under which it should not compete? If a country chooses to compete with another, how do the country's characteristics, as well as its offers, succeed in attracting FDI? Should a firm set up in one country exclusively and export to the other, or set up in both countries, engaging only in local production?

The interest in FDI over recent decades has led to many empirical investigations exploring the relationship between the flow and/or stock of FDI that a country receives and a variety of economic and political factors. The results of these empirical analyses have produced a rough consensus concerning the determinants of FDI. For example, the UN Economic Commission of Eu- 
rope's Economic Survey of Europe ${ }^{1}$ states there is a general agreement that the following characteristics are associated with larger flows of FDI: macroeconomic and political stability, developed infrastructure, good legal system and law enforcement, availability of skilled labor, foreign sector liberalization, location and country (market) size and natural endowment. ${ }^{2}$

Empirical investigations have also led to a series of stylized facts that are said to characterize FDI. A list of such facts is given in Markusen (1995), where he notes on the macro side: FDI has grown rapidly, it takes place largely between developed countries and within that context between subgroupings of countries, much of it is horizonal as well as intra-firm in nature, and evidence that it relates to differences in factor endowments or in returns to capital is still wanting. On the micro side he notes: FDI is industry specific, it seems to be associated with technologically advanced products and technologically advantaged labor forces, it is concentrated in firms with significant intangible assets, it may be negatively correlated with plant-level scale economies while positively correlated with firm size and longevity, and there are still questions concerning its relationship to shipping costs and trade barriers.

Recently, several papers have investigated whether or not the presence

\footnotetext{
${ }^{1}$ United Nations Economic Commission of Europe (2001), Economic Survey of Europe 2001:1, Ch. 5, p. 188. When specifically studying FDI patterns in transition economies, Garibaldi, Mora, Sahay and Zettelmeyer (2002) add privatization method and government red tape to these fundamentals.

${ }^{2}$ For recent contributions to this literature see, for example, Carr, Markusen and Maskus (2002), Garibaldi, Mora, Sahay and Zettelmeyer (2002), Borensztein, De Gregorio and Lee (1998), Lipsey (2001), and Saggi (2002).
} 
of corruption enhances or hinders a country's ability to attract FDI. ${ }^{3}$ Wei (2000b) finds that, taking account of both government restrictions on FDI as well as government incentives to encourage FDI, corruption is associated with a significant and substantial negative impact on FDI. Wei (2000a) estimates the cost of an increase in the corruption level in terms of a corresponding increase in the marginal tax rate. In a study focusing directly on Russia, Brock (1998) finds, in a regional investigation, that crime and risk are negatively correlated with FDI.

Empirical studies, however, by construction, are conditioned on the decisions made by the various countries to attract FDI, and thus cannot help us explore those decisions themselves. Yet, with the fall of communism and the subsequent emergence of market-based countries in Central and Eastern Europe, the decisions made by governments in regard to economic development, and to FDI in particular, have been pushed into higher profile. It has been widely remarked, for instance, that some countries in transition acquired significant flows of FDI, while others only a trickle. ${ }^{4}$ Should we conclude, for example, based on this uneven record, that the former group made wise decisions while the latter did not? Or, should we conclude that the former chose decisions to attract FDI, while the latter chose to pursue alternatives? While these questions seem natural in the context of economies in transition, they are more broadly applicable since an uneven pattern of distribution across

\footnotetext{
${ }^{3}$ See, for example, Shleifer and Vishny (1993), Mauro (1995), Bardhan (1997), Kaufman and Wei (1999), and Smarzynska and Wei (2000).

${ }^{4} \mathrm{See}$, for example, Campos and Coricelli (2000).
} 
countries is characteristic of FDI. Our work addresses some of these issues by making explicit both the decision processes of the countries attempting to attract FDI, and the decision process of the firm in choosing where, and how, to locate.

In our model we study two governments, each considering whether or not to compete to attract a foreign monopoly firm into its own domestic market. ${ }^{5}$ The competition, should it occur, would involve offering incentives to the firm. The incentives, which are costly for the governments to provide, lower the firm's marginal cost of production. Faced with the offers from each country, the firm must choose one of four options: to enter either of the markets, produce there and export to the other, to enter both markets simultaneously with only local production, or to reject all offers. We find conditions under which it would be optimal for one of the two countries not to compete with the other, preferring instead to import the commodity from the country that attracted the firm, rather than incurring the additional costs that would have been necessary to make its own economy more attractive to the foreign firm. We also show that when importing is a possibility, there are conditions under which, knowing that it will lose (win) the competition for the firm, the country nonetheless finds it optimal to (not) compete. Finally, we establish the relationship between the option chosen by the firm and the characteristics of the two governments trying to attract the firm.

\footnotetext{
${ }^{5}$ We make no distinction between a country and its government and use the terms interchangeably.
} 
Other gaming models that involve incentives offered by a government to attract a firm include Brander and Spencer (1987), Haaparanta (1996), Barros and Cabral (2000), and Janeba (2001). For example, Brander and Spencer can be interpreted in our framework by imagining that the two different policy options (taxation or tariff) are assigned to two separate countries, which otherwise share identical characteristics, and do not have the ability to export output to the other. Each country acts unilaterally in trying to attract FDI from a single firm. Haaparanta has a game of subsidies between the two countries, but the firm has already committed to investing in them and is only considering how to divide a known expenditure between the two countries. Barros and Cabral consider two countries already having decided to compete for a foreign firm using subsidies to lower the firm's marginal cost. The firm has only two choices: to set up and produce either in country 1 and export to country 2, or to set up and produce in country 2 and export to country 1. Janeba studies two countries, the smaller of which seeks to attract production from a firm in the larger country. In considering the established tax policy in the larger country, the firm, when offered a tax incentive that could possibly change from the smaller country, chooses to set up capacity and then produce in either of the two countries, or in both of them. Some other papers that relate to ours include Barros (1994), Motta (1992), Kaufman and Wei (1999), and Smarzynska and Wei (2000).

We make two main contributions to this literature. First, by allowing the government to decide to compete or not compete for FDI, we have enlarged 
its strategic choice set. This permits us to show that it is not necessarily because it would lose in a competition for FDI that a government would choose not to compete. Nor is it necessarily because a government would win a competition for FDI that it would choose to compete. Thus, we are able to

conclude that winning or losing a competition for FDI might be a strategic choice of a government. Second, by allowing the firm to choose among four options, we have enlarged the choice set of the firm. This allows us to show the relationship of the characteristics of the countries to the market structure that the firm would choose.

The plan of the paper is a follows. In Section 2 we present our model. In Section 3 we analyze the game for specific demand and cost functions. We present a discussion and conclusions in Section 4.

\section{The Model}

\subsection{Governments: The Game They Face}

There are two governments, $\mathrm{G}_{1}$ and $\mathrm{G}_{2}$, which are each interested in attracting a foreign monopoly firm to set up production of a homogeneous good in their country. The motivation for wishing to attract this firm and hence FDI may be the knowledge or technology spillovers that are said to accrue from FDI, or the lowering of existing unemployment that the FDI might afford. Each $\mathrm{G}_{i}$ makes an offer to the firm that we model as the marginal cost of producing its output that the firm would face if it located in that country. 
This summary number reflects the actual cost of production in that country, and depends on the given infrastructural of the country, the quality of its legal system, its level of corruption, etc. Each $\mathrm{G}_{i}$ chooses to compete for the firm $(C)$ or not to compete $(N C)$. If a $\mathrm{G}_{i}$ chooses not to compete, its offer of marginal cost remains at its initial value which we denote by $\omega_{i 0}, i=1,2$. If a $\mathrm{G}_{i}$ chooses to compete, then at a cost, the country offers the firm the marginal cost $\omega_{i}<\omega_{i 0}$. The profit maximizing firm makes its decision based on the offers given by the countries.

\subsection{The Firm: The Structure it Chooses}

Given two offers of marginal cost, $\omega_{1}$ and $\omega_{2}$ from $\mathrm{G}_{1}$ and $\mathrm{G}_{2}$, respectively, the firm chooses one of the following four options to maximize its profits:

Option 1: Accept the offer of $\omega_{1}$ from $\mathrm{G}_{1}$. Establish production in $\mathrm{G}_{1}$ for fixed cost $F$ and produce for the markets in $\mathrm{G}_{1}$ and $\mathrm{G}_{2}$ from $\mathrm{G}_{1}$. The marginal cost of producing a unit in $G_{1}$ and selling it in $G_{2}$ is augmented by trade costs $s_{1}$.

Option 2: Accept the offer of $\omega_{2}$ from $\mathrm{G}_{2}$. Establish production in $\mathrm{G}_{2}$ for fixed cost $F$ and produce for the markets in $\mathrm{G}_{2}$ and $\mathrm{G}_{1}$ from $\mathrm{G}_{2}$. The marginal cost of producing a unit in $\mathrm{G}_{2}$ and selling it in $\mathrm{G}_{1}$ is augmented by trade $\operatorname{costs} s_{2}$.

Option 3: Accept the offer of $\omega_{1}$ from $\mathrm{G}_{1}$ and the offer of $\omega_{2}$ from $\mathrm{G}_{2}$. Establish production in $\mathrm{G}_{1}$ for fixed cost $F$ and produce there only for the market in $\mathrm{G}_{1}$, and establish production in $\mathrm{G}_{2}$ for fixed cost $F$ and produce 
there only for the market in $\mathrm{G}_{2}$. We refer to this simultaneous establishment of production facilites in $\mathrm{G}_{1}$ and $\mathrm{G}_{2}$ as the multinational option. ${ }^{6}$

Option 4: Accept neither offer of $\omega_{1}$ or $\omega_{2}$ and set up in neither $\mathrm{G}_{1}$ nor $\mathrm{G}_{2}$.

Let $\pi_{1}\left(\omega_{1}\right), \pi_{2}\left(\omega_{2}\right), \pi\left(\omega_{1}, \omega_{2}\right)$, and $\pi_{0}\left(\omega_{1}, \omega_{2}\right)$ be the profit to the firm when the respective options are chosen. If we let $\pi^{*}=\max \left[\pi_{1}, \pi_{2}, \pi, \pi_{0}\right]$, then being a profit maximizer, the firm chooses Option 1 when $\pi^{*}=\pi_{1}$, Option 2 when $\pi^{*}=\pi_{2}$, Option 3 when $\pi^{*}=\pi$ and Option 4 when $\pi^{*}=$ $\pi_{0}$. When $\pi^{*}$ is not unique, we assume that the firm is indifferent between the options.

Assume that the firm is capable of producing a single, homogeneous commodity. We let $Q_{i}(P)$ be the demand function for this commodity produced in $\mathrm{G}_{i}$ and $P_{i}(\omega)$ be the firm's profit maximizing price in $\mathrm{G}_{i}$ when marginal cost is $\omega$. That is,

$$
P_{i}(\omega)=\arg \max _{P}\left[P Q_{i}(P)-\omega Q_{i}(P)-F\right]
$$

It is easily shown that

$$
\pi_{1}\left(\omega_{1}\right)=-\frac{Q_{1}^{2}\left(P_{1}\right)}{Q_{1}^{\prime}\left(P_{1}\right)}-F-\frac{Q_{2}^{2}\left(P_{12}\right)}{Q_{2}^{\prime}\left(P_{12}\right)}
$$

\footnotetext{
${ }^{6}$ Since the firm could already be producing in a home country before facing these options, the term multinational, as it has been used elsewhere, could apply to Option 1 and Option 2 as well. However, since in our model the firm need not have existed prior to this choice, we use the term multinational to distinguish Option 3 from Options 1 and 2.
} 
where $P_{1}=P_{1}\left(\omega_{1}\right)$ and $P_{12}=P_{2}\left(\omega_{1}+s_{1}\right)$,

$$
\pi_{2}\left(\omega_{2}\right)=-\frac{Q_{2}^{2}\left(P_{2}\right)}{Q_{2}^{\prime}\left(P_{2}\right)}-F-\frac{Q_{1}^{2}\left(P_{21}\right)}{Q_{1}^{\prime}\left(P_{21}\right)}
$$

where $P_{2}=P_{2}\left(\omega_{2}\right)$ and $P_{21}=P_{1}\left(\omega_{2}+s_{2}\right)$, and

$$
\pi\left(\omega_{1}, \omega_{2}\right)=-\frac{Q_{1}^{2}\left(P_{1}\right)}{Q_{1}^{\prime}\left(P_{1}\right)}-\frac{Q_{2}^{2}\left(P_{2}\right)}{Q_{2}^{\prime}\left(P_{2}\right)}-2 F
$$

We further assume that

$$
\pi_{0}\left(\omega_{1}, \omega_{2}\right)=0
$$

The assumption that the fixed $\operatorname{costs} F$ are identical in both countries could be relaxed but at the cost of complicating the notation further.

\subsection{Determining the Governments' Final Bids}

If the governments choose $(N C, N C)$, then they stay with their initial offers $\omega_{10}$ and $\omega_{20}$, which we assume are unacceptable to the firm, that is, $\pi_{1}\left(\omega_{10}\right)<$ 0 , and $\pi_{2}\left(\omega_{20}\right)<0 .{ }^{7}$ It follows that $\pi\left(\omega_{10}, \omega_{20}\right)<\pi_{1}\left(\omega_{10}\right)+\pi_{2}\left(\omega_{20}\right)<0$ and therefore $\pi^{*}=\pi_{0}$ and the firm sets up in neither country (Option 4).

If the governments choose $(C, N C)$, then $\mathrm{G}_{2}$ remains at the unacceptable offer of $\omega_{20}$, that is, $\pi_{2}\left(\omega_{20}\right)<0$. This, in turn, implies that for any $\omega_{1}>0$,

\footnotetext{
${ }^{7}$ This assumption is not required for what follows, but is made to reduce the number of cases to consider. In making this assumption, we have in mind countries, which for whatever reasons, would be unattractive places for the firm to establish production without some further action on their parts, e.g., the economies in transition in the immediate postSoviet period.
} 
$\pi_{1}\left(\omega_{1}\right)>\pi\left(\omega_{1}, \omega_{20}\right)$. Thus, for any $\omega_{1}>0$ such that $\pi_{1}\left(\omega_{1}\right)>0, \mathrm{G}_{1}$ would win the firm and export to $\mathrm{G}_{2}$. This can be thought of as a special case of Bertrand competition between the countries when only $\mathrm{G}_{1}$ is allowed to undercut the other offer. With $\mathrm{G}_{2}$ fixed at its unacceptable offer $\omega_{20}, \mathrm{G}_{1}$ would choose the offer that maximizes its net benefits, provided this offer were acceptable to the firm. We call the offer that maximizes $\mathrm{G}_{1}$ 's net benefits $\omega_{1 M}$. If $\omega_{1 M}$ were unacceptable to the firm, $\mathrm{G}_{1}$ would have to lower its offer to the point where profit for the firm were non-negative, assuming that this lower offer provided positive benefits to the country. We call the offer that produces zero profit to the firm $\omega_{1 B}$. We let $\alpha_{12}$ be the final offer of $\mathrm{G}_{1}$ which wins the firm, that is, $\alpha_{12}=\omega_{1 M}$ if $\omega_{1 M}$ is acceptable to the firm; otherwise, $\alpha_{12}=\omega_{1 B}$ if $\omega_{1 B}$ is acceptable to $G_{1}$. If $\omega_{1 B}$ is unacceptable to $G_{1}$, then $G_{1}$ is unwilling to provide an offer low enough to entice the firm. This would result in the firm not entering either market. We denote the net benefits to $\mathrm{G}_{1}$ and $\mathrm{G}_{2}$, respectively, when the firm is won by $\mathrm{G}_{1}$ (Option 1) at the offer $\alpha_{12}$ by $\left(B_{12}^{1}\left(\alpha_{12}\right), B_{12}^{2}\left(\alpha_{12}\right)\right)$. If $\omega_{1 B}$ is unacceptable to $\mathrm{G}_{1}$, then the payoffs are $(0,0)$.

Similarly, if the governments choose $(N C, C)$, we also have a special case of Bertrand competition. In this case, $\mathrm{G}_{1}$ remains at its initial offer $\omega_{10}$ and $\mathrm{G}_{2}$ chooses its net benefit maximizing value called $\omega_{2 M}$, or the point where the firm's non-negative profit is just sufficient to attract it to $\mathrm{G}_{2}$, called $\omega_{2 B}$. As above, we let $\alpha_{21}$ denote the winning bid that leads to the payoffs $\left(B_{21}^{1}\left(\alpha_{21}\right), B_{21}^{2}\left(\alpha_{21}\right)\right)$ to $\mathrm{G}_{1}$ and $\mathrm{G}_{2}$ respectively, with $\mathrm{G}_{2}$ winning the firm 
(Option 2). If $\omega_{2 B}$ is unacceptable to $\mathrm{G}_{2}$, then the payoffs are $(0,0)$.

If the governments choose $(C, C)$, they compete by undercutting each other in a Bertrand competition. Before we consider the consequences of this competition, we need additional definitions. Let $\left({ }_{i} B_{11}^{1}\left(\alpha_{i 1}^{*}\right),{ }_{i} B_{11}^{2}\left(\alpha_{i 2}^{*}\right)\right)$, $i=1, \ldots, 4$, represent the net benefits to $\mathrm{G}_{1}$ and $\mathrm{G}_{2}$, respectively, at the conclusion of the Bertrand competition when the final bids of the competition at which the benefits are evaluated are $\alpha_{i 1}^{*}$ and $\alpha_{i 2}^{*}$ for the respective countries and the firm chooses Option $i$. When $i=1$, the firm locates in $\mathrm{G}_{1}$ at the offer $\alpha_{11}^{*}$ and the benefits to $\mathrm{G}_{2}$ (the imports) just depend on $\alpha_{11}^{*}$, i.e., $\alpha_{12}^{*}=\alpha_{11}^{*}$. In this case, we call the common value $\alpha_{1}^{*}$. Similarly, when $i=2$, we set $\alpha_{2}^{*}=$ $\alpha_{22}^{*}=\alpha_{21}^{*}$. In the case when $i=3$, the benefits to each country depend on the (possibly different) bids of each $\mathrm{G}_{i}$ so we retain the notation of $\alpha_{3 j}^{*}, j=1,2$.

For any final offer of marginal cost to the firm when the governments choose $(C, C), \mathrm{G}_{1}$ can derive benefits in one of three ways depending on the result of the Bertrand competition: by production taking place in that country (Options 1 and 3) or by importing the product from $\mathrm{G}_{2}$ (Option 2). ${ }^{8}$ We assume that the net benefits to $\mathrm{G}_{1}$ of more production (Option 1) are greater than those of less production (Option 3). Furthermore, $\mathrm{G}_{1}$ would never make an offer which could produce a benefit less than the one it would receive if it imported the good from $\mathrm{G}_{2}$. Thus, the lowest offer that $\mathrm{G}_{1}$ would

\footnotetext{
${ }^{8}$ Recall that Option 4 yields zero net benefits.
} 
be willing to make, $\omega_{1 L}$, satisfies

$$
{ }_{3} B_{11}^{1}\left(\omega_{1 L}\right)={ }_{2} B_{11}^{1}\left(\omega_{1 L}\right) .
$$

Similarly, $\omega_{2 L}$ satisfies

$$
{ }_{3} B_{11}^{2}\left(\omega_{2 L}\right)={ }_{1} B_{11}^{2}\left(\omega_{2 L}\right)
$$

We are now able to address the question of the final bids from the Bertrand competition when the governments choose $(C, C)$.

Option 1 would be chosen by the firm if the bids $\omega_{1 L}$ and $\omega_{2 L}$ were made and if they satisfy $\pi_{1}\left(\omega_{1 L}\right) \geq \max \left[\pi_{2}\left(\omega_{2 L}\right), \pi\left(\omega_{1 L}, \omega_{2 L}\right), 0\right]$. However, when this inequality is strict, $\mathrm{G}_{1}$ does not have to make as low an offer as $\omega_{1 L}$ to win the firm. Instead, any offer between $\omega_{1 L}$ and $\alpha_{1}$, with $\alpha_{1}>\omega_{1 L}$, will win the firm for $\mathrm{G}_{1}$ where $\alpha_{1}$ satisfies $\pi_{1}\left(\alpha_{1}\right)=\max \left[\pi_{2}\left(\omega_{2 L}\right), \pi\left(\alpha_{1}, \omega_{2 L}\right), 0\right]$. Thus, the final bid of $\mathrm{G}_{1}$ leading to Option 1 is $\alpha_{1}^{*}, \alpha_{1}^{*} \in\left[\omega_{1 L}, \alpha_{1}\right]$, which will depend on the net benefits function. At the offer $\alpha_{1}^{*}, \mathrm{G}_{2}$ imports from $\mathrm{G}_{1}$.

Option 2 would be chosen in a similar fashion. The final offer $\alpha_{2}^{*}$ that would lead to Option 2 would satisfy $\alpha_{2}^{*} \in\left[\omega_{2 L}, \alpha_{2}\right]$ where $\alpha_{2}$ satisfies $\pi_{2}\left(\alpha_{2}\right)=\max \left[\pi_{1}\left(\omega_{1 L}\right), \pi\left(\omega_{1 L}, \alpha_{2}\right), 0\right]$. At the offer $\alpha_{2}^{*}, \mathrm{G}_{1}$ would import from $\mathrm{G}_{2}$.

Option 3, the multinational option, would be chosen by the firm if, at the lowest bids $\omega_{1 L}$ and $\omega_{2 L}, \pi\left(\omega_{1 L}, \omega_{2 L}\right) \geq \max \left[\pi_{1}\left(\omega_{1 L}\right), \pi_{2}\left(\omega_{2 L}\right), 0\right]$. However, when this inequality is strict, $\mathrm{G}_{1}$ would choose the offer of $\alpha_{31}^{*}$, 
$\alpha_{31}^{*} \in\left[\omega_{1 L}, \alpha_{31}\right]$, and $\mathrm{G}_{2}$ would choose the offer $\alpha_{32}^{*}, \alpha_{32}^{*} \in\left[\omega_{2 L}, \alpha_{32}\right]$ where $\alpha_{31}$ and $\alpha_{32}$ are as large an offer as $\mathrm{G}_{1}$ and $\mathrm{G}_{2}$, respectively, can make without changing the inequality. We later derive these values.

Option 4 is chosen by the firm when neither $\omega_{1 L}$ nor $\omega_{2 L}$ is acceptable to it. That is, $\pi_{1}\left(\omega_{1 L}\right)<0$, and $\pi_{2}\left(\omega_{2 L}\right)<0$, implying that $\pi\left(\omega_{1 L}, \omega_{2 L}\right)<0$, and therefore that $\pi^{*}=\pi_{0}$.

\subsection{Summarizing the Game the Governments Face}

Each $\mathrm{G}_{i}$ independently chooses whether to compete for FDI or not. The $\mathrm{G}_{i}$ 's share common knowledge of each other's characteristics as well as of the criteria upon which the choices are made. Each pair of choices induces a Bertrand-type competition, the final bids of which lead the firm to choose one of its four options. In a one-period model with full information, the offers made by the governments are credible. The option chosen by the firm, in turn, determines the net benefits accruing to each $\mathrm{G}_{i}$. In strategic form we have:

\section{Game Matrix 1}

$\mathbf{G}_{2}$

\begin{tabular}{|l|l|l|}
\hline & $C$ & $N C$ \\
\cline { 2 - 4 } $\mathbf{G}_{1} C$ & $\left({ }_{i} B_{11}^{1}\left(\alpha_{i 1}^{*}\right),{ }_{i} B_{11}^{2}\left(\alpha_{i 2}^{*}\right)\right), i=1, \ldots, 4$ & $\left(B_{12}^{1}\left(\alpha_{12}\right), B_{12}^{2}\left(\alpha_{12}\right)\right)$ or $(0,0)$ \\
\hline$N C$ & $\left(B_{21}^{1}\left(\alpha_{21}\right), B_{21}^{2}\left(\alpha_{21}\right)\right)$ or $(0,0)$ & $\left(B_{22}^{1}, B_{22}^{2}\right)=(0,0)$ \\
\hline
\end{tabular}




\subsection{Evaluating the Net Benefits}

In order to proceed in this investigation, we must assume some form of the net benefits functions or, equivalently, some objectives of the governments involved. The governments could be self-serving, corrupt, or concerned with the welfare of their respective populations. We choose to model the latter but note that the development below would be the same for any specification of these functions. In particular, we assume that when a firm establishes production within a country, that country benefits in two ways: first, by the consumer surplus it receives as a consequence of the production, and second, by additional benefits that accrue from the act of production itself. On the other hand, when a country only receives imports, its benefits are restricted to the consumer surplus. Firm profits provide no benefits to the host country since we assume they are completely repatriated to the firm's home country. The consumer surplus of own-country production and that of importing the product will differ as a function of the price at which the good is sold in each country.

Beyond consumer surplus, we assume a country receives additional benefits as a consequence of production. These may be due, for example, to additional employment (see Brander and Spencer (1987) and Barros and Cabral (2000)) or to additions to know-how gained from the technology transfer or spillover aspects of the particular production (see Borensztein, De Gregorio, and Lee (1998), Campos and Coricelli (2000), Saggi (2002), and UN Economic Commission of Europe (2001)). In particular, we assume 
for tractability that the additional benefits accruing from production are proportional to that production, with $k_{i}$ being the constant of proportionality for $\mathrm{G}_{i}$.

We assume that when $\mathrm{G}_{i}$ chooses to compete and wins the competition at the marginal cost, say $\omega$, it incurs a cost for having won the firm. This cost, for example, represents expenditures made by $\mathrm{G}_{i}$ to improve the physical infrastructure of the country or to reduce corruption. For $\mathrm{G}_{i}$ this cost of winning is given by the function $c_{i}(\omega)$, which is a decreasing convex function of the offer $\omega$. (Recall that it is more costly for a country to offer a lower $\omega$.) Furthermore, we assume for convenience that $c_{i}(\omega)$ is a proportional cost, that is, proportional to benefits. When $\mathrm{G}_{i}$ chooses to compete and loses the competition, we assume that it incurs a fixed proportional cost for having participated in the competition. We denote this cost by $d_{i}, i=1,2$, where $d_{i}$ is proportional to benefits. When $\mathrm{G}_{i}$ chooses not to compete, it incurs no costs, but might get some benefits from imports.

The net benefits for each country for the various outcomes of the game can now be described. For the outcome $(C, N C), \mathrm{G}_{2}$ remains at the unacceptable offer $\omega_{20}$ and $\mathrm{G}_{1}$ acts alone, making its most advantageous offer $\alpha_{12}$. If this 
offer wins the firm, the net benefits to $\mathrm{G}_{1}$ are

$$
\begin{aligned}
B_{12}^{1}= & {\left[\text { consumer surplus at } P_{1}\left(\alpha_{12}\right)+\text { additional benefits of production }\right] } \\
& \mathrm{x}\left[1-\text { cost of making the offer } \alpha_{12}\right] \\
= & {\left[\int_{P \geq P_{1}\left(\alpha_{12}\right)} Q_{1}(P) d P+k_{1}\left\{Q_{1}\left[P_{1}\left(\alpha_{12}\right)\right]+Q_{2}\left[P_{2}\left(\alpha_{12}+s_{1}\right)\right]\right\}\right]\left(1-c_{1}\left(\alpha_{12}\right)\right) }
\end{aligned}
$$

where $0 \leq c_{1}(\cdot) \leq 1$, and the net benefits to $\mathrm{G}_{2}$ are

$$
\begin{aligned}
B_{12}^{2} & =\left[\text { consumer surplus at } P_{2}\left(\alpha_{12}+s_{1}\right)\right] \\
& =\int_{P \geq P_{2}\left(\alpha_{12}+s_{1}\right)} Q_{2}(P) d P .
\end{aligned}
$$

Since under $(C, N C), \mathrm{G}_{1}$ could never receive imports if it failed to attract the firm, and since there is always a positive net benefit to $G_{1}$ from attracting the firm, the outcome $B_{12}^{1}=B_{12}^{2}=0$ is excluded here.

Similarly, for the outcome $(N C, C), \mathrm{G}_{2}$ acts alone, making its most advantageous offer $\alpha_{21}$. This offer wins the firm and the net benefits to $\mathrm{G}_{2}$ are

$$
B_{21}^{2}=\left[\int_{P \geq P_{2}\left(\alpha_{21}\right)} Q_{2}(P) d P+k_{2}\left\{Q_{2}\left[P_{2}\left(\alpha_{21}\right)\right]+Q_{1}\left[P_{2}\left(\alpha_{21}+s_{2}\right)\right]\right\}\right]\left(1-c_{2}\left(\alpha_{21}\right)\right)
$$


where $0 \leq c_{2}(\cdot) \leq 1$ and the net benefits to $\mathrm{G}_{1}$ are

$$
B_{21}^{1}=\int_{P \geq P_{1}\left(\alpha_{21}+s_{2}\right)} Q_{1}(P) d P
$$

Again, the outcome $B_{21}^{2}=B_{21}^{1}=0$ is excluded.

The benefits to the outcome $(N C, N C)$ are zero for each country since $\omega_{10}$ and $\omega_{20}$ are asssumed to be unacceptable to the firm.

The evaluation of the payoffs in the upper left corner of the game matrix, $(C, C)$, is more complicated because the payoffs depend on which option the firm chooses when confronted with the final offer of the competition. There are four options to consider. If the final bid of the Bertrand competition leads the firm to choose Option 1, then

$$
{ }_{1} B_{11}^{1}=\left[\int_{P \geq P_{1}\left(\alpha_{1}^{*}\right)} Q_{1}(P) d P+k_{1}\left\{Q_{1}\left[P_{1}\left(\alpha_{1}^{*}\right)\right]+Q_{2}\left[P_{2}\left(\alpha_{1}^{*}+s_{1}\right)\right]\right\}\right]\left(1-c_{1}\left(\alpha_{1}^{*}\right)\right)
$$

and

$$
{ }_{1} B_{11}^{2}=\left[\int_{P \geq P_{2}\left(\alpha_{1}^{*}+s_{1}\right)} Q_{2}(P) d P\right]\left(1-d_{2}\right)
$$

where $0 \leq d_{2} \leq 1$

If the final bid of the Bertrand competition leads the firm to choose Option 2, then

$$
{ }_{2} B_{11}^{2}=\left[\int_{P \geq P_{2}\left(\alpha_{2}^{*}\right)} Q_{2}(P) d P+k_{2}\left\{Q_{2}\left[P_{2}\left(\alpha_{2}^{*}\right)\right]+Q_{1}\left[P_{1}\left(\alpha_{2}^{*}+s_{2}\right)\right]\right\}\right]\left(1-c_{2}\left(\alpha_{2}^{*}\right)\right)
$$


and

$$
{ }_{2} B_{11}^{1}=\left[\int_{P \geq P_{1}\left(\alpha_{2}^{*}+s_{2}\right)} Q_{1}(P) d P\right]\left(1-d_{1}\right)
$$

where $0 \leq d_{1} \leq 1$.

If the final bids of the Bertrand competition lead the firm to choose Option 3, then the firm has accepted the final offers $\alpha_{31}^{*}$ and $\alpha_{32}^{*}$ from $\mathrm{G}_{1}$ and $\mathrm{G}_{2}$, respectively. In this case,

$$
{ }_{3} B_{11}^{1}=\left[\int_{P \geq P_{1}\left(\alpha_{31}^{*}\right)} Q_{1}(P) d P+k_{1} Q_{1}\left[P_{1}\left(\alpha_{31}^{*}\right)\right]\right]\left(1-c_{1}\left(\alpha_{31}^{*}\right)\right)
$$

and

$$
{ }_{3} B_{11}^{2}=\left[\int_{P \geq P_{2}\left(\alpha_{32}^{*}\right)} Q_{2}(P) d P+k_{2} Q_{2}\left[P_{2}\left(\alpha_{32}^{*}\right)\right]\right]\left(1-c_{2}\left(\alpha_{32}^{*}\right)\right) .
$$

If the final bid of the Bertrand competition leads the firm to choose Option 4 , then ${ }_{4} B_{11}^{1}={ }_{4} B_{11}^{2}=0$.

\section{Analyzing the Game for Specific Demand and Cost Functions}

For the remainder of the paper, we assume specific forms of the demand functions and cost functions that enable us to explore the equilibria of Game Matrix 1. We let $Q_{1}(P)=e^{-P}, Q_{2}(P)=f e^{-P}$, and $c_{i}(\omega)=e^{-\beta_{i} \omega}$, where $P, f, \beta_{i}>0, i=1,2$. The parameter $f$ reflects the relative size of the second 
market. We do not assume that this is less than one. In fact, as we later show, the value of one for $f$ is not critical. The parameter $\beta_{i}$ in the cost function inversely reflects the cost (difficulty) to $\mathrm{G}_{i}$ of implementing the offer $\omega$. If $\beta_{i}$ is sufficiently small, then even a relatively high offer has a large cost. Conversely, a sufficiently large value of $\beta_{i}$ implies a small cost for a relatively low offer.

Using these specifications, the game, in strategic form, can be evaluated as follows:

\section{Game Matrix 2}

\begin{tabular}{l|l|l|l|}
\multicolumn{3}{c}{$\mathbf{G}_{2}$} \\
\cline { 2 - 4 } $\mathbf{G}_{1}$ & $C$ & $N C$ \\
\cline { 2 - 4 } & $C$ & $\left({ }_{i} B_{11}^{1}\left(\alpha_{i 1}^{*}\right),{ }_{i} B_{11}^{2}\left(\alpha_{i 1}^{*}\right)\right), i=1, \ldots, 4$ & $\left(B_{12}^{1}\left(\alpha_{12}\right), B_{12}^{2}\left(\alpha_{12}\right)\right)$ \\
\cline { 2 - 4 } & $\left(B_{21}^{1}\left(\alpha_{21}\right), B_{21}^{2}\left(\alpha_{21}\right)\right)$ & $\left(B_{22}^{1}, B_{22}^{2}\right)=(0,0)$ \\
\hline
\end{tabular}

where for $(C, C)$ :

$$
\begin{aligned}
& \left({ }_{1} B_{11}^{1},{ }_{1} B_{11}^{2}\right)=\left({ }_{1} K_{11}^{1} e^{-\alpha_{1}^{*}}\left[1-e^{\left.-\beta_{1} \alpha_{1}^{*}\right]},{ }_{1} K_{11}^{2} e^{-\alpha_{1}^{*}}\right)\right. \\
& \quad \text { with }{ }_{1} K_{11}^{1}=e^{-1}\left[1+k_{1}+k_{1} f e^{-s_{1}}\right] \text { and }{ }_{1} K_{11}^{2}=f e^{-\left(1+s_{1}\right)}\left[1-d_{2}\right], \\
& \left({ }_{2} B_{11}^{1},{ }_{2} B_{11}^{2}\right)=\left({ }_{2} K_{11}^{1} e^{-\alpha_{2}^{*}},{ }_{2} K_{11}^{2} e_{1}^{-\alpha_{2}^{*}}\left[1-e^{\left.-\beta_{2} \alpha_{2}^{*}\right]}\right)\right. \\
& \quad \text { with }{ }_{2} K_{11}^{1}=e^{-\left(1+s_{2}\right)}\left[1-d_{1}\right] \text { and }{ }_{2} K_{11}^{2}=e^{-1}\left[f+k_{2} f+k_{2} e^{-s_{2}}\right] \\
& \left({ }_{3} B_{11}^{1},{ }_{3} B_{11}^{2}\right)=\left({ }_{3} K_{11}^{1} e^{-\alpha_{31}^{*}}\left[1-e^{-\beta_{1} \alpha_{31}^{*}}\right],{ }_{3} K_{11}^{2} e^{-\alpha_{32}^{*}}\left[1-e^{\left.-\beta_{2} \alpha_{32}^{*}\right]}\right)\right. \\
& \quad \text { with }{ }_{3} K_{11}^{1}=e^{-1}\left[1+k_{1}\right] \text { and }{ }_{3} K_{11}^{2}=e^{-1} f\left[1+k_{2}\right] \\
& \left({ }_{4} B_{11}^{1},{ }_{4} B_{11}^{2}\right)=(0,0)
\end{aligned}
$$$$
\text { where for }(C, N C) \text { : }
$$$$
\left(B_{12}^{1}, B_{12}^{2}\right)=\left(K_{12}^{1} e^{-\alpha_{12}}\left[1-e^{-\beta_{1} \alpha_{12}}\right], K_{12}^{2} e^{-\alpha_{12}}\right)
$$ 
with $K_{12}^{1}=e^{-1}\left[1+k_{1}+k_{1} f e^{-s_{1}}\right]$ and $K_{12}^{2}=f e^{-\left(1+s_{1}\right)}$;

where for $(N C, C)$ :

$$
\begin{aligned}
& \left(B_{21}^{1}, B_{21}^{2}\right)=\left(K_{21}^{1} e^{-\alpha_{21}}, K_{21}^{2} e^{-\alpha_{21}}\left[1-e^{-\beta_{2} \alpha_{21}}\right]\right) \\
& \quad \text { with } K_{21}^{1}=e^{-\left(1+s_{2}\right)} \text { and } K_{21}^{2}=e^{-1}\left[f+k_{2} f+k_{2} e^{-s_{2}}\right]
\end{aligned}
$$

and where for $(N C, N C)$ :

$\left(B_{22}^{1}, B_{22}^{2}\right)=(0,0)$.

The entries in the upper left position represent the net benefits to each $\mathrm{G}_{i}$ when the Bertrand competition leads the firm to choose one of its four options. In the upper right and lower left positions, when only one government is trying to undercut the other, there is only one possible choice that the firm can make, i.e., to produce entirely in one country. The lower right entry reflects the assumption that the initial offers of marginal cost are unacceptable to the firm.

To complete the description of the game matrix, we must evaluate $\alpha_{12}$, $\alpha_{21}$, and $\alpha_{i j}^{*}, i=1, \ldots, 4 ; j=1,2$. Since $\alpha_{12}$ and $\alpha_{21}$ depend on $\omega_{j M}$ and $\omega_{j B}, j=1,2$, and since $\alpha_{i j}^{*}$ depends on $\omega_{j L}, j=1,2$, we next evaluate these quantities.

\subsection{Determining $\omega_{1 M}, \omega_{2 M}, \omega_{1 B}, \omega_{2 B}, \omega_{1 L}, \omega_{2 L}$}

For the outcome $(C, N C), \mathrm{G}_{1}$ acts alone and, by our assumption about $\alpha_{12}$, is guaranteed to win the firm. Thus the final bid will either be $\omega_{1 M}$ or $\omega_{1 B}$. If $\alpha_{12}=\omega_{1 M}, \mathrm{G}_{1}$ maximizes its net benefits. Referring to the evaluations in 
Game Matrix 2, this maximum must satisfy

$$
\omega_{1 M}=\arg \max _{\omega} e^{-\omega}\left(1-e^{-\beta_{1} \omega}\right)
$$

It follows that $e^{-\beta_{1} \omega_{1 M}}=\frac{1}{1+\beta_{1}}$ or $e^{-\omega_{1 M}}=\left(\frac{1}{1+\beta_{1}}\right)^{\frac{1}{\beta_{1}}}$. The maximum net benefits achievable for $\mathrm{G}_{1}$ are $K_{12}^{1}\left(\frac{\beta_{1}}{1+\beta_{1}}\right)\left(\frac{1}{1+\beta_{1}}\right)^{\frac{1}{\beta_{1}}}$. When $\alpha_{12}=\omega_{1 B}, \mathrm{G}_{1}$ offers the largest marginal cost that is acceptable to the firm, that is, the marginal cost that produces non-negative profit for the firm. This offer satisfies $\pi_{1}\left(\omega_{1 B}\right)=0$, and using equations (1), the offer can be written as $e^{-\omega_{1 B}}=\frac{e F}{1+f e^{-s_{1}}}$.

Similarly, when the choices are $(N C, C)$, and when $\alpha_{21}=\omega_{2 M}$, this maximum satisfies $e^{-\beta_{2} \omega_{2 M}}=\frac{1}{1+\beta_{2}}$ and the maximum net benefits achievable for $\mathrm{G}_{2}$ are $K_{21}^{2}\left(\frac{\beta_{2}}{1+\beta_{2}}\right)\left(\frac{1}{1+\beta_{2}}\right)^{\frac{1}{\beta_{2}}}$. Also, when $\alpha_{21}=\omega_{2 B}$, this value must satisfy $e^{-\omega_{2 B}}=\frac{e F}{f+e^{-s_{2}}}$.

Finally, we determine the lowest bid that $\mathrm{G}_{1}$ would be willing to make in the Bertrand competition that occurs when the governments choose $(C, C)$. As discussed above, since the loss of the firm under these governmental choices can still provide benefits via imports, there will be a lowest offer that each country would be willing to make. We can evaluate these lower bids using the results in Game Matrix 2. If a given bid of $\omega$ by $\mathrm{G}_{1}$ were the final bid, then if it lost the firm completely to $\mathrm{G}_{2}$ (Option 2), $\mathrm{G}_{1}$ would receive net benefits ${ }_{2} K_{11}^{1} e^{-\omega}$. On the other hand, if it won it, it would either win the entire production (Option 1) or part of the multinational firm 
(Option 3). Winning part of the multinational firm yields less net benefits than winning the entire production. Thus, if the bid of $\omega$ wins, then it yields at least ${ }_{3} K_{11}^{1} e^{-\omega}\left(1-e^{-\beta_{1} \omega}\right)$. Since $\omega_{1 L}$ is the value of $\omega$ for which $\mathrm{G}_{1}$ would be indifferent to winning a part of the multinational firm or to losing the firm completely and instead taking imports from $\mathrm{G}_{2}, \omega_{1 L}$ satisfies ${ }_{2} K_{11}^{1} e^{-\omega}=$ ${ }_{3} K_{11}^{1} e^{-\omega}\left(1-e^{-\beta_{1} \omega}\right)$ or $e^{-\beta_{1} \omega_{1 L}}=1-\gamma_{1}$ or $\omega_{1 L}=-\frac{1}{\beta_{1}} \ln \left(1-\gamma_{1}\right)$ where

$\gamma_{1}=\frac{{ }_{2} K_{11}^{1}}{{ }_{3} K_{11}^{1}}$. Similarly, we have for $\mathrm{G}_{2}$ that $\omega_{2 L}$ satisfies $e^{-\beta_{2} \omega_{2 L}}=1-\gamma_{2}$ or

$\omega_{2 L}=-\frac{1}{\beta_{2}} \ln \left(1-\gamma_{2}\right)$ where $\gamma_{2}=\frac{{ }_{1} K_{11}^{2}}{{ }_{3} K_{11}^{2}}$. Note that $\gamma_{1}=\frac{e^{-s_{2}\left(1-d_{1}\right)}}{1+k_{1}}$ and that $\omega_{1 L}$ is monotonically increasing in $\gamma_{1}$. Thus, the lower bound $\omega_{1 L}$ is decreasing in $k_{1}, s_{2}$ and $d_{1}$. Similarly, $\omega_{2 L}$ is decreasing in $k_{2}, s_{1}$ and $d_{2}$.

We assume that when the firm faces a choice between two options that yield the same profit, it will be indifferent to the choice and we assign the choice depending on the context. Furthermore, if a government faces two choices that yield the same net benefits, we assume that it will be indifferent to the choice and we assign the choice depending on the context.

\subsection{Determining the Equilibria}

The game outlined above is one of complete information. As such, the question arises as to whether it is ever desirable for a government to compete for FDI if it knows that it will lose the firm in the competition. Conversely, would a country that knows it would win the competition choose not to compete? To address these questions, we explore the equilibria associated with this game. We begin with a few definitions. 
Let $K=\frac{f+e^{-s_{2}}}{1+f e^{-s_{1}}}$. Notice that $K \gtreqless 1$ if and only if $f \gtreqless \frac{1-e^{-s_{2}}}{1-e^{-s_{1}}}$. Thus, $K$ is a measure of relative size of the market in $\mathrm{G}_{2}$, adjusted for the costs of selling in both markets. As a result, we refer to $K$ as the size index. We defined $F$ as the fixed cost of setting up production facilities in each country. However, the units of $F$ remain to be specified. We measure the size of $F$ in units of revenue minus variable cost. Since the setup cost is identical in both countries, we arbitrarily choose the revenue minus variable cost of $G_{2}$ at its lowest value, $\omega_{2 L}$. Revenue minus variable cost in $\mathrm{G}_{2}$ is proportional to $e^{-\omega_{2}}$ so we define the size of the relative fixed cost as $R=\frac{e F}{f e^{-\omega_{2 L}}}$ where the scale $\frac{e}{f}$ is chosen for later convenience. Note that since $f e^{-\left(1+\omega_{2 L}\right)}$ is the quantity demanded at the price $P_{2}\left(\omega_{2 L}\right), R$ can be interpreted as the fixed costs per quantity sold.

Proposition 1 Let $G_{1}$ and $G_{2}$ choose $(C, C)$ and let $\alpha_{1}=\omega_{2 L}-\ln K+$ $\min \left[\ln \left(\frac{K e^{-s_{1}}}{1-R}\right), 0\right]$. If the relative fixed cost $R$ satisfies $R \leq 1$, and if the minumum bids satisfy $\omega_{1 L} \leq \alpha_{1}$, then $\pi^{*}=\pi_{1}$ for any final bid by $G_{1}$ between $\omega_{1 L}$ and $\alpha_{1}$ and final bid by $G_{2}$ of $\omega_{2 L}$. Thus, for any such bids, $G_{1}$ wins the firm in the Bertrand competition (Option 1).

\section{Proof See Appendix.}

Proposition 1 focuses on the key ingredients that lead the firm to set up its production in $\mathrm{G}_{1}$ : the relative fixed cost, the final bids the countries are willing to make, and the distinguishing characteristics of the countries. How small $\omega_{1 L}$ needs to be relative to $\omega_{2 L}$ for $\pi^{*}=\pi_{1}$ depends in part on the 
ratio $\frac{K e^{-s_{1}}}{1-R}$. The smaller this ratio relative to unity, the smaller $\omega_{1 L}$ needs to be. This ratio depends not only on $R$ but also on the relative country sizes $(f)$ and the trade costs of selling goods in the other markets $\left(s_{1}\right.$ and $\left.s_{2}\right)$. Note that if $R$ is sufficiently large, then the profit of the firm would become negative. Thus, an upper bound on $R$ is needed to preclude the firm from rejecting entirely the bid of $\mathrm{G}_{1}$.

From Section 3.1, the assumption of Proposition 1, $\omega_{1 L} \leq \alpha_{1}$, may be written as $\frac{1}{\beta_{1}} \ln \left(1-\gamma_{1}\right) \geq \frac{1}{\beta_{2}} \ln \left(1-\gamma_{2}\right)+\ln K-\min \left[\ln \left(\frac{K e^{-s_{1}}}{1-R}\right), 0\right]$. This involves the comparison of two "cost-benefit" type terms. Since $c_{i}(\omega)=e^{-\beta_{i} \omega}$ is a decreasing function of $\beta_{i}$ for each $\omega$, we can think of $\frac{1}{\beta_{i}}$ as a simple measure of the cost to $\mathrm{G}_{i}$ of making an offer of marginal cost $\omega$. Also, $1-\gamma_{1}=1-\frac{e^{-s_{2}}\left(1-d_{1}\right)}{1+k_{1}}$ can be thought of as a measure of bargaining advantage to $G_{1}$ in attracting the firm, with a similar interpretation for $1-\gamma_{2}$ for $G_{2}$. Thus, this assumption, which compares the product of these terms, captures the relative strengths of the two governments in the Bertrand competition.

A consequence of this proposition is that even if the two countries are identical, i.e., $\beta_{1}=\beta_{2}, s_{1}=s_{2}, k_{1}=k_{2}, d_{1}=d_{2}$, and $f=K=1$, it is not clear what choice the firm will make without further information. This follows since, for these values, the conditions required in the proposition for Option 1 to be chosen reduce to $1-e^{-s_{1}} \leq R \leq 1$. If, however, $R<1-e^{-s_{1}}$, then Option 3, the multinational choice, would be made by the firm as we show below in the discussion following Proposition 5.

Another consequence of $\omega_{1 L} \leq \alpha_{1}$ is that the winner of the firm need 
not necessarily be the country with the lower final bid. For example, if $s_{1}=s_{2}, k_{1}=k_{2}, d_{1}=d_{2}$, and $K<1$, then the condition for Option 1 becomes $\omega_{1 L} \leq \omega_{2 L}+b$, where $b>0$ when $K e^{-s_{1}} \geq 1-R$, suggesting that, ceteris paribus, $\mathrm{G}_{1}$ could win the firm even if its lowest offer were greater than that of $\mathrm{G}_{2}$, i.e., $\omega_{1 L}>\omega_{2 L}$. We note that this comports with the recent empirical findings of, for example, Brock (1998) and Carr, Markusen and Maskus (2002) that lowest wage costs alone do not necessarily attract FDI.

Another form of competition that has been described in the literature for attracting a firm is based on trade barriers (see, for example, Brander and Spencer (1987) and Motta (1992)). Although we do not incorporate trade barriers as strategic variables in our game, Proposition 1 provides some indication as to the impact of such barriers. For example, if $\mathrm{G}_{2}$ were to impose large import tariffs, $s_{1}$ would become large. As a result, $\gamma_{2}$ would decrease, giving $\mathrm{G}_{2}$ the ability to offer better terms to the firm. The effect of this shift would be that the firm would be less likely to setup production in $\mathrm{G}_{1}$. If both countries imposed large tariffs, then it would become more likely that the firm would choose the multinational option or to locate in neither $\mathrm{G}_{1}$ nor $\mathrm{G}_{2}$. These considerations are explored below in Proposition 5 .

Proposition 1 establishes a range of bids within which $\mathrm{G}_{1}$ wins the firm. However, the particular bid that wins the Bertrand competition, $\alpha=\alpha_{1}^{*}$, is the one in this interval that maximizes the net benefits to $\mathrm{G}_{1}$. We next identify this offer.

Proposition 2 Under the conditions of Proposition 1, the final bid of the 
Bertrand competition corresponding to the choices $(C, C)$, can take on only one of three values; that is $\alpha_{1}^{*}=\alpha_{1}$ if $\omega_{1 L} \leq \alpha_{1} \leq \omega_{1 M}, \alpha_{1}^{*}=\omega_{1 M}$ if $\omega_{1 L} \leq$ $\omega_{1 M} \leq \alpha_{1}$, and $\alpha_{1}^{*}=\omega_{1 L}$ if $\omega_{1 M} \leq \omega_{1 L} \leq \alpha_{1}$.

\section{Proof See Appendix.}

The next proposition establishes conditions under which the bids $\alpha_{12}$ and $\alpha_{21}$, corresponding to the off-diagonal choices of the governments, can be uniquely identified.

Proposition 3 Let $e^{-1} \leq \frac{e F}{1+f e^{-s_{1}}} \leq 1$ and $e^{-1} \leq \frac{e F}{f+e^{-s_{2}}} \leq 1$. Then,

(1) the equations $\left(\frac{1}{1+x}\right)^{\frac{1}{x}}=\frac{e F}{1+f e^{-s_{1}}}$ and $\left(\frac{1}{1+x}\right)^{\frac{1}{x}}=\frac{e F}{f+e^{-s_{2}}}$ have unique solutions $x=\beta_{1 B}$ and $x=\beta_{2 B}$, respectively, and

(2) if $c_{i}(\omega)=e^{-\beta_{i B} \omega}$, then $\omega_{i M}=\omega_{i B}, i=1,2$, and $\alpha_{12}=\omega_{1 M}=\omega_{1 B}$ and $\alpha_{21}=\omega_{2 M}=\omega_{2 B}$.

\section{Proof See Appendix.}

We are now able to establish the conditions that lead to unique equilibria of the game. We show that there are cases in which a government would compete for FDI knowing it will lose the competition, as well as other cases in which a government would choose to not compete for FDI even knowing that it would win the competition.

Proposition 4 Let $c_{i}(\omega)=e^{-\beta_{i B} \omega}, i=1,2$, where $\beta_{i B}$ are determined under the conditions of Proposition 3. Furthermore, let $1-K e^{-s_{1}} \leq R \leq 1$, and $\omega_{1 L} \leq \omega_{2 L}-\ln K$. Then, 
(1) if $1-d_{1}>\frac{h_{1}}{K}$ where $h_{1}=\frac{1+k_{1}}{1+k_{1}+k_{1} f e^{-s_{1}}}$ and $1-d_{2}>\frac{f}{f+e^{-s_{2}}} R,(C, C)$ is the unique Nash equilibrium of the game. Furthermore, at $(C, C)$ the firm chooses Option 1, i.e., $G_{1}$ wins the firm;

(2) if $1-d_{1}>\frac{h_{1}}{K}$ and $1-d_{2}<\frac{f}{f+e^{-s_{2}}} R,(C, N C)$ is the unique Nash equilibrium of the game. Furthermore, at $(C, N C)$ the firm chooses Option 1, i.e., $G_{1}$ wins the firm;

(3) if $1-\frac{1}{1+\beta_{1 B}}<\frac{h_{2}}{K}$ where $h_{2}=\frac{e^{-s_{2}}}{1+k_{1}+k_{1} f e^{-s_{1}}}$ and $1-d_{2}>\frac{f}{f+e^{-s_{2}}} R$, $(N C, C)$ is the unique Nash equilibrium of the game. Furthermore, at $(N C, C)$ the firm chooses Option 2, i.e., $G_{2}$ wins the firm.

\section{Proof See Appendix.}

By fixing the cost functions at the parameters $\beta_{1 B}$ and $\beta_{2 B}$, we have assumed in Proposition 4 that each $\mathrm{G}_{i}$, when acting to maximize its own net benefits, would choose to offer the firm its country's breakeven value. It is also assumed that, at these parameter values, the "cost-benefit" factor of $\mathrm{G}_{1}$, described in the discussion following Proposition 1, is sufficiently large compared to that of $\mathrm{G}_{2}$. When we add two more assumptions, that the costs of participating in the competition and losing, $d_{1}$ and $d_{2}$, are not too large, we show in part $(1)$ of Proposition 4 that $(C, C)$ is the unique Nash equilibrium. Since this is a game of complete information, part (1) demonstrates that there are instances in which a government $\left(\mathrm{G}_{2}\right.$, here), knowing that it will lose the competition for FDI, still finds it in its interest to compete. This occurs because the result of the Bertrand competition forces $\mathrm{G}_{1}$ 's marginal cost, and thereby its price, lower. As a result, imports in $\mathrm{G}_{2}$ are cheaper and $\mathrm{G}_{2}$ 's 
consumer surplus increases enough to offset the cost of participating in the competition. Note that small values of $d_{i}$ are not sufficient to satisfy these inequalities, and, in fact, if either $d_{i}=0$, then the respective inequalities could or could not be satisfied, depending on the values of $K, h_{i}$, etc.

As the last remarks suggest, a delicate balance in the parameters must exist to make it desirable for $\mathrm{G}_{2}$ to compete knowing it will lose. In part (2) of Proposition 4 we show that, as one might expect, there are cases where, if a government knows it will lose, it will choose not to compete.

In part (3) of Proposition 4 we invoke another assumption that puts a bound on $\beta_{1 B}$. Combining this assumption with the assumption that led to the conclusion that $\mathrm{G}_{2}$ would opt to compete, we show that $(N C, C)$ is the unique Nash equilibrium of the game. In this game of complete information, and knowing therefore that it would win the Bertrand competition, $\mathrm{G}_{1}$ nonetheless finds it advantageous not to compete. Part of the explanation of this is seen in the assumption that $\beta_{1 B}$ is small, or $\frac{1}{\beta_{1 B}}$ is large, implying that the cost of making the offer that would result from the Bertrand competition is too costly an offer to make. Again, some care must be taken in interpreting the upper bound of this parameter as this upper bound depends on the parameters $K, h_{i}$, etc.

How dependent are the conclusions of Proposition 4 on the selection of parameters that led to the choice of Option 1 resulting from the Bertrand competition? To answer this question, we must consider parameter values that would lead the firm to choose other options and show that the three 
Nash equilibria would still hold. Because of the symmetry between Option 1 and Option 2, we omit this case, and move to explore the situation where the Bertrand competition would lead to Option 3.

Proposition 5 Let $G_{1}$ and $G_{2}$ choose $(C, C)$. If the relative fixed cost $R$ satisfies $R \leq 1-K e^{-s_{1}}$, and if the minimum bids satisfy $\omega_{2 L}-\ln \left[e^{s_{1}}(1-R)\right] \leq$ $\omega_{1 L} \leq \omega_{2 L}-\ln \left[e^{-s_{2}}+f R\right]$, then $\pi^{*}=\pi$ for any final bid by $G_{1}$ between $\omega_{1 L}$ and $\alpha_{31}$, where $\alpha_{31}$ satisfies $e^{-\alpha_{31}}=e^{-\left(\omega_{2 L}+s_{2}\right)}+e F$, and any final bid by $G_{2}$ between $\omega_{2 L}$ and $\alpha_{32}$, where $\alpha_{32}$ satisfies $e^{-\alpha_{32}}=e^{-\left(\omega_{1 L}+s_{1}\right)}+\frac{e F}{f}$. Thus, for any such pair of bids, the firm elects to become a multinational (Option 3).

\section{Proof See Appendix.}

It is not surprising that a condition that makes the multinational option attractive to the firm is one that forces the relative fixed cost $R$ to be small enough to warrant paying the fixed cost twice. The bound on $R$ depends on, and cannot be determined separate from, the parameters that characterize the countries. But, smallness of the relative fixed cost is not enough for the firm to elect to become a multinational. A second condition imposes a balancing requirement between the final possible offers of the governments. However, this balancing requirement is, by itself, not enough to cause the firm to choose the multinational option. For example when the two countries are identical, i.e., $\beta_{1}=\beta_{2}, s_{1}=s_{2}, k_{1}=k_{2}, d_{1}=d_{2}$, and $f=K=1$, it follows that $\omega_{1 L}=\omega_{2 L}$ and the multinational option will be chosen if and only if $R \leq 1-e^{-s_{1}}$. In fact, even if $K \neq 1$, so long as $\omega_{1 L}=\omega_{2 L}$, the second 
condition will be satisfied if and only if $R \leq 1-K e^{-s_{1}}$. In general, similarity of the countries, plus a low relative fixed cost, are both needed to produce the multinational outcome.

Proposition 5 establishes a range of bids within which the firm chooses to become a multinational. However, the particular bids that win the Bertrand competition, $\alpha_{31}^{*}$ and $\alpha_{32}^{*}$, are the ones that maximize the net benefits of the respective governments.

We are now able to establish the unique Nash equilibria when the Bertrand competition corresponding to $(C, C)$ leads the firm to choose to become a multinational.

Proposition 6 Let $c_{i}(\omega)=e^{-\beta_{i B} \omega}, i=1,2$, where $\beta_{i B}$ are determined under the conditions of Proposition 3. Furthermore, let $R \leq 1-K e^{-s_{1}}$, and $\omega_{2 L}-$ $\ln \left[e^{s_{1}}(1-R)\right] \leq \omega_{1 L} \leq \omega_{2 L}-\ln \left[e^{-s_{2}}+f R\right]$. Then,

(1) if $1-d_{1}>\frac{1}{f+e^{-s_{2}}}$ and $1-d_{2}>\frac{f}{1+f e^{-s_{1}}},(C, C)$ is the unique Nash equilibrium of the game. Furthermore, at $(C, C)$ the firm chooses Option 3, i.e., the firm sets up production in both $G_{1}$ and $G_{2}$, becoming a multinational;

(2) if $1-d_{1}>\frac{1}{f+e^{-s_{2}}}$ and $1-\frac{1}{1+\beta_{2 B}}<K \frac{e^{-s_{1}}}{1+k_{2}},(C, N C)$ is the unique Nash equilibrium of the game. Furthermore, at $(C, N C)$ the firm chooses Option 1, i.e., $G_{1}$ wins the firm;

(3) if $1-\frac{1}{1+\beta_{1 B}}<\frac{e^{-s_{2}}}{K\left(1+k_{1}\right)}$ and $1-d_{2}>\frac{f}{1+f e^{-s_{1}}},(N C, C)$ is the unique Nash equilibrium of the game. Furthermore, at $(N C, C)$ the firm chooses Option 2, i.e., $G_{2}$ wins the firm. 


\section{Proof See Appendix.}

The conditions on $R, \omega_{1 L}$, and $\omega_{2 L}$ in Proposition 6 imply that, should the $\mathrm{G}_{i}$ choose $(C, C)$, the firm would choose Option 3. However, the choice of the governments to compete needs some further conditions. These limit the size of the costs of competing and losing, i.e., the $d_{i}$. In part (1), where these limits are satisfied, $(C, C)$ becomes the unique Nash equilibrium. In this case, each government chooses partial production over the choice to import.

In part (2) of Proposition 6, the firm chooses Option 1. Here, $\mathrm{G}_{2}$ chooses to import from $\mathrm{G}_{1}$ rather than to compete and have the firm set up production in $\mathrm{G}_{2}$ for the market in $\mathrm{G}_{2}$ alone. The conditions that lead to this choice by $\mathrm{G}_{2}$ are that its market is not too small, and that its cost of reducing its offer of marginal cost to the firm is large. Again, interpreting the bounds on size and cost require knowledge of the parameters. Part (3) has a parallel interpretation to part (2).

Proposition 6, together with Proposition 4, show that there are cases in which the governments will choose to compete or will choose not to compete whatever the forseen decision the firm would make in each situation.

\section{Discussion and Conclusions}

The model that we propose involves a game between two governments competing to attract a single firm. Each government (country) is defined by five

characteristics: a demand function $Q_{i}$, the $\operatorname{costs} c_{i}(\cdot)$ and $d_{i}$ of competing to 
acquire FDI, the trade cost $s_{i}$ of producing a unit of the good and selling it in the other country, the size, 1 or $f$, of its market, and an objective function $B_{i}$ of the government seeking FDI. The firm chooses its market structure by making one of four choices: to produce in $\mathrm{G}_{1}$ and export to $\mathrm{G}_{2}$, to produce in $G_{2}$ and export to $G_{1}$, to produce in both $G_{1}$ and $G_{2}$ with no exports (the multinational option), and to produce in neither $G_{1}$ nor $G_{2}$. We derive the unique Nash equilibria corresponding to different characteristics of these countries. This allows us to establish the relationship of the countries' characteristics to the choice of participating or abstaining in a competition to acquire FDI. Also, by establishing the links between the decisions of the governments to compete and the structure of the firm, we are able to distinguish the conditions that would lead to the firm to become a multinational, or alternatively, to set up production in one country and export to the other.

In many of the models relating to FDI, it is assumed either that the firm has committed itself to engaging in FDI or that a government has committed itself to competing to attract FDI. Our results suggest that firms or governments with such commitments have special characteristics that make these commitments an outcome of a benefit-maximizing strategy. We show that these special characteristics that lead a government to compete do not necessarily imply that that government has an advantage in the competition. This suggests that there is a heterogenity in the types of countries that compete to attract FDI. Of the countries that attract FDI, for example, some of them had the right characteristics to win in a competition for FDI and some 
of them won by default. Of the ones that won the firm through competition, some shared the firm with other countries (the multinational option), and some did not. Complicating these subgroupings further is the group of countries that would have won in the competition but chose for other reasons not to compete. The recognition of these groupings might have some consequences for empirical studies.

The actual cost to the government of making a final offer to attract a firm plays an important role in our conclusions. By interpreting the source of this cost, we can explore some of the consequences when the competing governments are of different types. For example, the economies in transition at the start of the transition process represented competing governments with different, albeit weak, infrastructures. When a country has a weak infrastructure, we could assume that it would be very costly for it to make all the improvements necessary to reduce substantially the marginal cost that the firm would face in setting up production there. Since the parameter $\frac{1}{\beta_{i}}$ reflects the size of this cost in our model, small values of $\beta_{i}$ would characterize governments with poor infrastructures. Ceteris paribus, this would force the firm to seek production elsewhere, as seen in Propositions 4 and 6. Similarly, a large cost could also be the consequence of certain types of governmental corruption. For a corrupt government to make a given offer of marginal cost to a firm, it would have to spend more to make that offer than would a non-corrupt government. Thus, for such corrupt governments, $\frac{1}{\beta_{i}}$ would be large and would tend, again, to dissuade the firm from setting 
up production. However, in any competitive situation, it is really the relative cost of one government, as compared with that of the other, that is the critical comparison.

We also establish the relationship between the characteristics of the governments and the structure of the firm. As a result, we are able to add to a number of observations made in the literature. First, it is often argued that the size of a market is a magnet for FDI. Our results show that the size of the market plays a more nuanced role in attracting FDI. If $f$, the size of country 2 , is large relative to country $1(f \rightarrow \infty)$, then $K$ approaches the value $e^{s_{1}}$ and $\mathrm{G}_{1}$ would still attract the firm if $\omega_{1 L}+s_{1}<\omega_{2 L}$ as Proposition 1 shows. Furthermore, even if this last inequality were reversed, the firm might choose to split its production between the countries (the multinational option) as in Proposition 5. This choice would depend on $\lim _{f \rightarrow \infty} f R$. Of course, when the two countries are identical except for size, leading to $\omega_{1 L}=\omega_{2 L}$, then as $f \rightarrow \infty$, country 1 would never acquire the firm in its entirety. Thus the importance of size is in direct relationship to the similarity between the countries. As the characteristics diverge, the importance of size is tempered by these distinguishing characteristics. ${ }^{9}$

\footnotetext{
${ }^{9}$ Note, for example, the recent decision of Peugeot to build a factory in Slovakia rather than in Poland. "Poland had originally been tipped as the favored site, and news that the carmaker had chosen its smaller southern neighbor shook Warsaw." (International Herald Tribune (IHT), "Slovak plant extends Peugeot's reach in East," January 16, 2003, p. 10.) Also, according to the head of Poland's super-ministry for economy, labor and social affairs: "If we can't resolve the problems with our roads, infrastructure and logistics, we have to expect such decisions - despite Poland's other advantages." (Reuters News Article, "Peugeot Citroen picks Slovakia for new plant," January 15, 2003.)
} 
Second, low production costs are sometimes referred to as another magnet for FDI. Again, our model suggests a more nuanced role for production costs. As discussed above following Proposition 1, the lowest offer of marginal cost does not necessarily attract the firm. Also, the relative sizes of the two final offers by themselves, and indeed, even if they were equal, do not determine whether the firm produces exclusively in one country or divides its production between the two countries. Furthermore, two countries with the same final offers could have different characteristics since in our model the final offers depend on a function of $\beta_{i}, s_{i}$, and $k_{i}$. Thus, we would expect that the firm might be attracted to countries with very different characteristics.

Third, it is sometimes argued that by raising import tariffs, a government can entice a firm to set up production in that country. As discussed following Proposition 1 , if, say $\mathrm{G}_{1}$, were to engage in this behavior, then ceteris paribus, the firm would be less likely to locate in $G_{2}$. But, if both $G_{1}$ and $G_{2}$ raised their tariffs, the firm would not necessarily go to either country alone, but could choose the multinational option. In general, the consequences of raising tariffs are difficult to forecast since the raising of the values of $s_{1}$ and $s_{2}$ affect the lowest bids of the countries as well as the size index and the relative fixed costs.

In sum, we show that to assume at the outset that two countries compete for FDI diverts attention from the strategic nature of such a decision. By studying this decision, we are not only able to demonstrate how a country's characteristics relate to this choice, but also to establish the relationship 
between this choice and the decision of the firm as to where to locate and produce.

\section{Appendix}

\subsection{Proof of Proposition 1.}

Proof Let $\omega_{1} \in\left[\omega_{1 L}, \alpha_{1}\right]$ and $\omega_{2}=\omega_{2 L}$ be the final bids. Evaluating equations (1), we have that $\pi_{1} \geq \pi_{2}$ if $e^{-\left(1+\omega_{1}\right)}-F+f e^{-\left(1+\omega_{1}+s_{1}\right)} \geq$ $f e^{-\left(1+\omega_{2}\right)}-F+e^{-\left(1+\omega_{2}+s_{2}\right)}$ or if $e^{-\omega_{1}}\left[1+f e^{-s_{1}}\right] \geq e^{-\omega_{2}}\left[f+e^{-s_{2}}\right]$ or if $e^{-\omega_{1}} \geq$ $e^{-\omega_{2}} K$ or if $\omega_{1} \leq \omega_{2}-\ln K$. Also, $\pi_{1} \geq \pi$ if $e^{-\left(1+\omega_{1}\right)}-F+f e^{-\left(1+\omega_{1}+s_{1}\right)} \geq$ $e^{-\left(1+\omega_{1}\right)}+f e^{-\left(1+\omega_{2}\right)}-2 F$ or if $e^{-\omega_{1}} \geq e^{s_{1}}\left(e^{-\omega_{2}}-\frac{e F}{f}\right)=e^{s_{1}} e^{-\omega_{2}}(1-R)$ since $\omega_{2}=\omega_{2 L}$. So, $\pi_{1} \geq \pi$ if $\omega_{1} \leq \omega_{2}-s_{1}-\ln (1-R)=\omega_{2}-\ln K+\ln \left(\frac{K e^{-s_{1}}}{1-R}\right)$. Thus, for $\pi_{1}$ to be no less than both $\pi_{2}$ and $\pi, \omega_{1} \leq \omega_{2}-\ln K+\min \left[\ln \left(\frac{K e^{-s_{1}}}{1-R}\right), 0\right]=$ $\alpha_{1}$ which was assumed.

To complete the proof, we must show that $\pi_{1} \geq 0$ at these offers, i.e., that $e^{-\omega_{1}} \geq \frac{e F}{1+f e^{-s_{1}}}$. By the definition of $R, \frac{e F}{1+f e^{-s_{1}}}=\frac{f}{f+e^{-s_{2}}} K e^{-\omega_{2 L}} R$. Thus, $\pi_{1} \geq 0$ if $\omega_{1} \leq \omega_{2 L}-\ln K-\ln \left(\frac{f R}{f+e^{-s_{2}}}\right)$. Since $R \leq 1$, the right-hand-side of the last inequality is greater than $\alpha_{1}$, and it follows that $\pi_{1} \geq 0$.

\subsection{Proof of Proposition 2.}

Proof Under Proposition 1, any offer between $\omega_{1 L}$ and $\alpha_{1}$ will win the firm for $\mathrm{G}_{1}$. Therefore, $\mathrm{G}_{1}$ will choose the offer to maximize its net benefits 
from Option 1. The net benefits function is proportional to $e^{-\omega}\left(1-e^{-\beta_{1} \omega}\right)$. This function is unimodal with a unique maximum satisfying $e^{-\beta_{1} \omega_{1 M}}=\frac{1}{1+\beta_{1}}$. Furthermore, the net benefits function is monotonically increasing for $0 \leq$ $\omega \leq \omega_{1 M}$ and monotonically decreasing for $\omega>\omega_{1 M}$. Thus, if $\omega_{1 M}>\alpha_{1}$, the net benefits will be maximized at $\alpha_{1}^{*}=\alpha_{1}$. When $\omega_{1 L}<\omega_{1 M} \leq \alpha_{1}, \alpha_{1}^{*}=\omega_{1 M}$ and when $\omega_{1 M} \leq \omega_{1 L}, \alpha_{1}^{*}=\omega_{1 L}$.

\subsection{Proof of Proposition 3.}

Proof Since $\left(\frac{1}{1+x}\right)^{\frac{1}{x}}$ is a continuous, strictly increasing function that goes from $e^{-1}$ to 1 as $x$ goes from 0 to $\infty$, and since, by assumption, both $\frac{e F}{1+f e^{-s_{1}}}$ and $\frac{e F}{f+e^{-s_{2}}}$ are in the interval $\left[e^{-1}, 1\right]$, part (1) follows. To show part $(2)$, recall that $e^{-\omega_{i M}}=\left(\frac{1}{1+\beta_{i}}\right)^{\frac{1}{\beta_{i}}}$. Setting $\beta_{i}=\beta_{i B}$ implies that $e^{-\omega_{1 M}}=$ $\left(\frac{1}{1+\beta_{1 B}}\right)^{\frac{1}{\beta_{1 B}}}=\frac{e F}{1+f e^{-s_{1}}}=e^{-\omega_{1 B}}$. Similarly, $e^{-\omega_{2 M}}=\left(\frac{1}{1+\beta_{2 B}}\right)^{\frac{1}{\beta_{2 B}}}=\frac{e F}{f+e^{-s_{2}}}=$ $e^{-\omega_{2 B}}$. Thus, the two possible values that $\alpha_{12}$ can take, $\omega_{1 M}$ and $\omega_{1 B}$, are the same as are the two possible values that $\alpha_{21}$ can take, $\omega_{2 M}$ and $\omega_{2 B}$.

\subsection{Proof of Proposition 4.}

Proof We first evaluate Game Matrix 2. The lower right element corresponding to $(N C, N C)$, is $(0,0)$. The upper right position corresponding to $(C, N C)$ requires the specification of $\alpha_{12}$ which, by Proposition 3, for $\beta_{1}=\beta_{1 B}$, is $\alpha_{12}=\omega_{1 M}=\omega_{1 B}$. Similarly, for the lower left position, $\alpha_{21}=\omega_{2 M}=\omega_{2 B}$. In the upper left position the governments choose $(C, C)$ 
and our assumptions are the same as in Proposition 1. From Proposition 1 we have that $e^{-\omega_{1 L}} \geq e^{-\alpha_{1}}=e^{-\omega_{2 L}} K$. Also, by Proposition $1, e^{-\alpha_{1}} \geq \frac{e F}{1+f e^{-s_{2}}}$. But $\frac{e F}{1+f e^{-s_{2}}}=e^{-\omega_{1 B}}=e^{-\omega_{1 M}}$ by Proposition 3. Thus, $e^{-\omega_{1 L}} \geq e^{-\alpha_{1}} \geq e^{-\omega_{1 M}}$, and by Proposition 2 (see proof), the final bid of the Bertrand competion is $\alpha_{1}^{*}=\alpha_{1}$ and the firm chooses Option 1. Game Matrix 2 is, therefore,

\section{$\mathbf{G}_{2}$}

\begin{tabular}{|l|l|l|}
\hline & $C$ & $N C$ \\
\hline $\mathbf{G}_{1}$ & ${ }_{1} B_{11}^{1}={ }_{1} K_{11}^{1} e^{-\alpha_{1}}\left(1-e^{-\beta_{1 B} \alpha_{1}}\right)$ & $B_{12}^{1}=K_{12}^{1} e^{-\omega_{1 B}}\left(1-e^{-\beta_{1 B} \omega_{1 B}}\right)$ \\
& ${ }_{1} B_{11}^{2}={ }_{1} K_{11}^{2} e^{-\alpha_{1}}$ & $B_{12}^{2}=K_{12}^{2} e^{-\omega_{1 B}}=K_{12}^{2} \frac{e F}{1+f e^{-s_{1}}}$ \\
\cline { 2 - 3 } & $B_{21}^{1}=K_{21}^{1} e^{-\omega_{2 B}}=K_{21}^{1} \frac{e F}{f+e^{-s_{2}}}$ & $B_{22}^{1}=0$ \\
& $B_{21}^{2}=K_{21}^{2} e^{-\omega_{2 B}}\left(1-e^{-\beta_{2 B} \omega_{2 B}}\right)$ & $B_{22}^{2}=0$ \\
\hline
\end{tabular}

To show part (1), we show that $C$ is a dominant strategy for each government. We first show that $C$ is a dominant strategy for $\mathrm{G}_{1}$. Since $B_{12}^{1}>0$, we need only show that ${ }_{1} B_{11}^{1}>B_{21}^{1}$. Since $e^{-\omega_{1 L}} \geq e^{-\alpha_{1}}$, then $1-e^{-\beta_{1 B} \alpha_{1}} \geq 1-$ $e^{-\beta_{1 B} \omega_{1 L}}$. Earlier, we showed that $e^{-\beta_{1 B} \omega_{1 L}}=1-\gamma_{1}$. So, ${ }_{1} B_{11}^{1}={ }_{1} K_{11}^{1} e^{-\alpha_{1}}(1-$ $\left.e^{-\beta_{1 B} \alpha_{1}}\right) \geq \gamma_{11} K_{11}^{1} e^{-\alpha_{1}}=\gamma_{11} K_{11}^{1} e^{-\omega_{2 L}} K$. From the fact that $1 \geq R=\frac{e F / f}{e^{-\omega_{2 L}}}$, we have ${ }_{1} B_{11}^{1} \geq \gamma_{11} K_{11}^{1} K \frac{e F}{f}=\gamma_{1{ }_{1}} K_{11}^{1} K \frac{\left(f+e^{-s_{2}}\right)}{f} e^{-\omega_{2 B}} \geq \gamma_{11} K_{11}^{1} K e^{-\omega_{2 B}}$. Finally, ${ }_{1} B_{11}^{1}>B_{21}^{1}$ if $\gamma_{1}{ }_{1} K_{11}^{1} K>K_{21}^{1}$ or if $\frac{e^{-s_{2}\left(1-d_{1}\right)}}{1+k_{1}}\left(e^{-1}\left(1+k_{1}+k_{1} f e^{-s_{1}}\right)\right) K>$ $e^{-\left(1+s_{2}\right)}$ or if $\left(1-d_{1}\right) K>\frac{1+k_{1}}{1+k_{1}+k_{1} f e^{-s_{1}}}$ or if $\left(1-d_{1}\right) K>h_{1}$ which was assumed to hold. We finally show that $C$ is a dominant strategy for $\mathrm{G}_{2}$. Since $B_{21}^{2}>0$, we need to show that ${ }_{1} B_{11}^{2}>B_{12}^{2}$ or that ${ }_{1} K_{11}^{2} e^{-\alpha_{1}}>K_{12}^{2} e^{-\omega_{1 B}}$. Rewriting the last inequality, we must show $\left(1-d_{2}\right) K e^{-\omega_{2 L}}>\frac{e F}{1+f e^{-s_{1}}}$ or 
$1-d_{2}>\frac{f R}{K\left(1+f e^{-s_{1}}\right)}=\frac{f}{f+e^{-s_{2}}} R$, which is assumed to hold. Thus, the statement of part (1) holds.

To show part (2), we show that $C$ is a dominant strategy for $\mathrm{G}_{1}$ and that ${ }_{1} B_{11}^{2}<B_{12}^{2}$. The demonstration that $C$ is a dominant strategy for $\mathrm{G}_{1}$ is the same as in part (1) since we assume that $1-d_{1}>\frac{h_{1}}{K}$. To show ${ }_{1} B_{11}^{2}<B_{12}^{2}$, we need show that $\frac{e F}{1+f e^{-s_{1}}}>\left(1-d_{2}\right) e^{-\omega_{2 L}} K$. But this inequality is the same as $1-d_{2}<\frac{f R}{K\left(1+f e^{-s_{1}}\right)}=\frac{f}{f+e^{-s_{2}}} R$ which is assumed.

To show part (3), we show that $C$ is a dominant strategy for $\mathrm{G}_{2}$ and that ${ }_{1} B_{11}^{1}<B_{21}^{1}$. Since it is assumed that $1-d_{2}>\frac{f}{f+e^{-s_{2}}} R$, it follows as in part (1) that $C$ is a dominant strategy for $\mathrm{G}_{2}$. To show that ${ }_{1} B_{11}^{1}<B_{21}^{1}$, note that ${ }_{1} B_{11}^{1}={ }_{1} K_{11}^{1} e^{-\alpha_{1}}\left(1-e^{-\beta_{1 B} \alpha_{1}}\right) \leq{ }_{1} K_{11}^{1} e^{-\omega_{1 M}}\left(1-e^{-\beta_{1 B} \omega_{1 M}}\right)$ since $\omega_{1 M}$ maximizes this function. Furthermore, $e^{-\beta_{1 B} \omega_{1 M}}=\frac{1}{1+\beta_{1 B}}$, so ${ }_{1} B_{11}^{1} \leq$ ${ }_{1} K_{11}^{1} \frac{\beta_{1 B}}{\beta_{1 B}+1} e^{-\omega_{1 M}}$. Also, $B_{21}^{1}=K_{21}^{1} e^{-\omega_{2 B}}$. Since $\omega_{1 M}=\omega_{1 B},{ }_{1} B_{11}^{1}<B_{21}^{1}$ if ${ }_{1} K_{11}^{1} \frac{\beta_{1 B}}{\beta_{1 B}+1} \frac{e F}{1+f e^{-s_{1}}}<K_{21}^{1} \frac{e F}{f+e^{-s_{2}}}$ or if $1-\frac{1}{\beta_{1 B}+1}<\frac{e^{-s_{2}}}{K\left(1+k_{1}+k_{1} f e^{-s_{1}}\right)}=\frac{h_{2}}{K}$ which is assumed.

\subsection{Proof of Proposition 5.}

Proof First we show that for any final offers $\omega_{1}$ and $\omega_{2}$ for $G_{1}$ and $G_{2}$, Option 3 would be chosen by the firm if $\max \left[e^{-\left(\omega_{2}+s_{2}\right)}+e F, 2 e F-f e^{-\omega_{2}}\right] \leq$ $e^{-\omega_{1}} \leq e^{s_{1}}\left(e^{-\omega_{2}}-\frac{e F}{f}\right)$. To show this, we show that for offers satisfying these inequalities, $\pi \geq \pi_{1}, \pi \geq \pi_{2}$, and $\pi \geq 0$. Since $\pi=e^{-\left(1+\omega_{1}\right)}+f e^{-\left(1+\omega_{2}\right)}-2 F$ and $\pi_{1}=e^{-\left(1+\omega_{1}\right)}-F+f e^{-\left(1+\omega_{1}+s_{1}\right)}, \pi \geq \pi_{1}$ if $e^{-\omega_{1}} \leq e^{s_{1}}\left(e^{-\omega_{2}}-\frac{e F}{f}\right)$. Since $\pi_{2}=f e^{-\left(1+\omega_{2}\right)}-F+e^{-\left(1+\omega_{2}+s_{2}\right)}$, it follows that $\pi \geq \pi_{2}$ if $e^{-\omega_{1}} \geq e^{-\left(\omega_{2}+s_{2}\right)}+e F$. 
For $\pi \geq 0, e^{-\omega_{1}} \geq 2 e F-f e^{-\omega_{2}}$.

The assumed inequalities involving $\omega_{1 L}$ and $\omega_{2 L}$ imply that $e^{-\omega_{2 L}}\left(e^{-s_{2}}+\right.$ $f R) \leq e^{-\omega_{1 L}} \leq e^{-\omega_{2 L}} e^{s_{1}}(1-R)$. Since $e^{-\omega_{2 L}} R=e F / f$, the last inequality can be written as $e^{-\left(\omega_{2 L}+s_{2}\right)}+e F \leq e^{-\omega_{1 L}} \leq e^{s_{1}}\left(e^{-\omega_{2 L}}-\frac{e F}{f}\right)$. Furthermore,

$e^{-\left(\omega_{2 L}+s_{2}\right)}+e F \geq 2 e F-f e^{-\omega_{2 L}}$ since this inequality holds when $\left(1+\frac{e^{-s_{2}}}{f}\right) \geq R$ and $R$ was assumed to satisfy $R \leq 1-K e^{-s_{1}}$. So for the final bids $\omega_{1 L}$ and $\omega_{2 L}, \pi^{*}=\pi$, and Option 3 is chosen by the firm.

If $\mathrm{G}_{2}$ were to offer a higher bid than $\omega_{2 L}$, so long as the right inequality held, the same conclusion would hold. Also, if $\mathrm{G}_{1}$ were to offer a higher bid so long as the left inequality held, the same conclusion would hold. Thus, $\mathrm{G}_{2}$ could raise its bid up to $\alpha_{32}$ satisfying $e^{-\omega_{1 L}}=e^{s_{1}}\left(e^{-\alpha_{32}}-\frac{e F}{f}\right)$ and $\mathrm{G}_{1}$ could raise its bid up to $\alpha_{31}$ satisfying $e^{-\alpha_{31}}=e^{-\left(\omega_{2 L}+s_{2}\right)}+e F$. If either government were to raise its bid beyond these values the other country would acquire the entire firm.

\subsection{Proof of Proposition 6.}

Proof We first evaluate the Game Matrix 2. Under the assumptions of this proposition, the payoffs in each of the positions of the game matrix stay the same as those in Proposition 4 except for the upper left entry. In the upper left position the conditions of Proposition 5 hold so that the firm chooses Option 3 and each $\mathrm{G}_{i}$ receives the net benefits of local production for its final bids. Game Matrix 2 is, therefore, 


\section{$\mathbf{G}_{2}$}

\begin{tabular}{|l|l|l|}
\hline & $C$ & $N C$ \\
\hline \multirow{4}{*}{$\mathbf{G}_{1}$} & ${ }_{3} B_{11}^{1}={ }_{3} K_{11}^{1} e^{-\alpha_{31}^{*}}\left(1-e^{-\beta_{1 B} \alpha_{31}^{*}}\right)$ & $B_{12}^{1}=K_{12}^{1} e^{-\omega_{1 B}}\left(1-e^{-\beta_{1 B} \omega_{1 B}}\right)$ \\
\cline { 2 - 4 } & ${ }_{3} B_{11}^{2}={ }_{3} K_{11}^{2} e^{-\alpha_{32}^{*}}\left(1-e^{-\beta_{2 B} \alpha_{32}^{*}}\right)$ & $B_{12}^{2}=K_{12}^{2} e^{-\omega_{1 B}}=K_{12}^{2} \frac{e F}{1+f e^{-s_{1}}}$ \\
\cline { 2 - 4 }$N C$ & $B_{21}^{1}=K_{21}^{1} e^{-\omega_{2 B}}=K_{21}^{1} \frac{e F}{f+e^{-s_{2}}}$ & $B_{22}^{1}=0$ \\
& $B_{21}^{2}=K_{21}^{2} e^{-\omega_{2 B}}\left(1-e^{-\beta_{2 B} \omega_{2 B}}\right)$ & $B_{22}^{2}=0$ \\
\hline
\end{tabular}

where from Proposition $5, \omega_{i L} \leq \alpha_{3 i}^{*} \leq \alpha_{3 i}$.

To show part (1), we show that $C$ is a dominant strategy for each government. For $\mathrm{G}_{1}$, we need only show that ${ }_{3} B_{11}^{1}>B_{21}^{1}$ since $B_{12}^{1}>0$. Thus, we need show that $e^{-1}\left(1+k_{1}\right) e^{-\alpha_{31}^{*}}\left(1-e^{-\beta_{1 B} \alpha_{31}^{*}}\right)>e^{-\left(1+s_{2}\right)} \frac{e F}{f+e^{-s_{2}}}$. Since $\alpha_{31}^{*} \geq \omega_{1 L}, 1-e^{-\beta_{1 B} \alpha_{31}^{*}} \geq 1-e^{-\beta_{1 B} \omega_{1 L}}=1-\left(1-\gamma_{1}\right)=\gamma_{1}=\frac{e^{-s_{2}\left(1-d_{1}\right)}}{1+k_{1}}$. Thus, to show that $C$ is a dominant strategy for $\mathrm{G}_{1}$, it is enough to show that $e^{-\alpha_{31}^{*}}>\frac{1}{1-d_{1}} \frac{e F}{f+e^{-s_{2}}}$. Since $\alpha_{31}^{*} \leq \alpha_{31}$, it is enough to show that $e^{-\alpha_{31}}>$ $\frac{1}{1-d_{1}} \frac{e F}{f+e^{-s_{2}}}$. From Proposition 5, $e^{-\alpha_{31}}=e^{-\left(\omega_{2 L}+s_{2}\right)}+e F$ so the last inequality may be written as $e^{-\left(\omega_{2 L}+s_{2}\right)}+e F\left[1-\frac{1}{\left(1-d_{1}\right)\left(f+e^{-s_{2}}\right)}\right]>0$. This inequality will hold if the coefficient of $e F$ is non-negative. Since $1-\frac{1}{\left(1-d_{1}\right)\left(f+e^{\left.-s_{2}\right)}\right.} \geq 0$ if $1-d_{1} \geq \frac{1}{f+e^{-s_{2}}}$, the inequality is satisfied by assumption and $C$ is a dominant strategy for $\mathrm{G}_{1}$.

To show $C$ is a dominant strategy for $\mathrm{G}_{2}$ we need only show that ${ }_{3} B_{11}^{2}>$ $B_{12}^{2}$ since $B_{21}^{2}>0$. Since $\omega_{2 L} \leq \alpha_{32}^{*} \leq \alpha_{32}$, the same argument for $\mathrm{G}_{2}$ implies that we need only show that $e^{-\alpha_{32}}=e^{-\left(\omega_{1 L}+s_{1}\right)}+\frac{e F}{f}>\frac{e F}{\left(1-d_{2}\right)\left(1+f e^{\left.-s_{1}\right)}\right.}$. This inequality will hold if $\frac{1}{f} \geq \frac{1}{\left(1-d_{2}\right)\left(1+f e^{-s_{1}}\right)}$ or if $1-d_{2}>\frac{f}{1+f e^{-s_{1}}}$ which was assumed. 
To show part (2), we show that $C$ is a dominant strategy for $\mathrm{G}_{1}$ and that ${ }_{3} B_{11}^{2}<B_{12}^{2}$. The demonstration that $C$ is a dominant strategy for $\mathrm{G}_{1}$ is the same as in part (1) since, by assumption $1-d_{1}>\frac{1}{f+e^{-s_{2}}}$. To show that ${ }_{3} B_{11}^{2}<B_{12}^{2}$, we need to show that ${ }_{3} K_{11}^{2} e^{-\alpha_{32}^{*}}\left(1-e^{-\beta_{2 B} \alpha_{32}^{*}}\right)<K_{12}^{2} \frac{e F}{1+f e^{-s_{1}}}$ or $e^{-\alpha_{32}^{*}}\left(1-e^{-\beta_{2 B} \alpha_{32}^{*}}\right)<\frac{e^{-s_{1}}}{1+k_{2}} \frac{e F}{1+f e^{-s_{1}}}$. The left-hand-side of this last inequality is no greater than its maximum value and $e^{-\omega_{2 M}}\left(1-e^{-\beta_{2 B} \omega_{2 M}}\right)=e^{-\omega_{2 B}}(1-$ $\left.\frac{1}{1+\beta_{2 B}}\right)=\frac{e F}{f+e^{-s_{2}}}\left(1-\frac{1}{1+\beta_{2 B}}\right)$ (the last two equations follow since when $\beta_{2}=$ $\left.\beta_{2 B}, \omega_{2 M}=\omega_{2 B}\right)$. Thus, ${ }_{3} B_{11}^{2}<B_{12}^{2}$ if $1-\frac{1}{1+\beta_{2 B}}<\frac{e^{-s_{1}}}{1+k_{2}} \frac{f+e^{-s_{2}}}{1+f e^{-s_{1}}}=K \frac{e^{-s_{1}}}{1+k_{2}}$ which is assumed.

To show part (3), we show that $C$ is a dominant strategy for $\mathrm{G}_{2}$ and that ${ }_{3} B_{11}^{1}<B_{21}^{1}$. Since $1-d_{2}>\frac{f}{1+f e^{-s_{1}}}$, it follows from above that $C$ is a dominant strategy for $\mathrm{G}_{2}$. To show that ${ }_{3} B_{11}^{1}<B_{21}^{1}$, we need to show $e^{-\alpha_{31}^{*}}\left(1-e^{-\beta_{1 B} \alpha_{31}^{*}}\right)<\frac{e^{-s_{2}}}{1+k_{1}} \frac{e F}{f+e^{-s_{2}}}$. The left-hand-side of this inequality is no greater than $e^{-\omega_{1 M}}\left(1-e^{-\beta_{1 B} \omega_{1 M}}\right)=e^{-\omega_{1 B}}\left(1-\frac{1}{1+\beta_{1 B}}\right)=\frac{e F}{1+f e^{-s_{1}}}\left(1-\frac{1}{1+\beta_{1 B}}\right)$. Thus, ${ }_{3} B_{11}^{1}<B_{21}^{1}$ if $1-\frac{1}{1+\beta_{1 B}}<K^{-1} \frac{e^{-s_{2}}}{1+k_{1}}$ which is assumed.

*We thank the participants of the Economics Seminar at ESSEC for their helpful comments. Part of this work was done while visiting ESSEC Business School, Cergy, France, and we thank ESSEC for its hospitality. Correspondence: B.G. Katz, bkatz@stern.nyu.edu, Stern School of Business, NYU, 44 W. 4th Street, New York, NY 10012; tel: 212998 0865, fax: 2129954218. 


\section{References}

[1] Bardhan, Pranab (1997). "Corruption and Development: A Review of Issues," Journal of Economic Literature, 35(3), pp. 1320-1346.

[2] Barros, Pedro P. (1994). "Market Equilibrium Effects of Incentives to Foreign Direct Investment," Economics Letters, 44, pp. 153-157.

[3] Barros, Pedro P. and Luis M. B. Cabral (2000). "Competing for Foreign Direct Investment," Review of International Economics, 8(2), pp. $360-371$.

[4] Barros, Pedro P. and Luis M. B. Cabral (2002). "Government Subsides to Foreign Direct Investment," mimeo.

[5] Borensztein, E., J. De Gregorio, and J-W. Lee (1998). "How Does foreign Direct Investment Affect Economic Growth?" Journal of International Economics, 45, pp. 115-135.

[6] Brander, James A. and Barbara J. Spencer (1987). "Foreign Direct Investment with Unemployment and Endogenous Taxes and Tariffs," Journal of International Economics, 22, pp. 257-279.

[7] Brock, Gregory J. (1998). "Foreign Direct Investment in Russia's Regions 1993-95: Why so Little and Where has it Gone?," Economics of Transition, 6(2), pp. 349-360.

[8] Campos, Navro F. and Fabrizio Coricelli (2002). "Growth in Transition: What We Know, What We Don't and What We Should," Journal of 
Economic Literature, 40(3), pp. 793-837.

[9] Carr, David L., James R. Markusen and Keith E. Maskus (2002). "Competition for Multinational Investment in Developing Countries: Human Capital, Infrastructure and Market Size," mimeo.

[10] European Bank for Reconstruction and Development (2001). Transition Report Update 2001, Ch. 2, Cross-Border Capital Flows.

[11] Garibaldi, Pietro, Nada Mora, Ratna Sahay and Jeromin Zettelmeyer (2002). "What Moves Capital to Transition Economies?" IMF Working Paper No. 64.

[12] Haaparanta, Pertti (1996). "Competition for Foreign Direct Investment," Journal of Public Economics, 63, pp, 141- 53.

[13] Horstmann, Ignatius J. and James R. Markusen (1995). "Exploring New Markets: Direct Investment, Contractual Relations and the Multinational Enterprise," NBER Working Paper No. 5029.

[14] International Herald Tribune, "Slovak Plant Extends Peugeot's reach in East," January 16, 2003.

[15] Janeba, Eckhard (2002). "Attracting FDI in a Politically Risky World," International Economic Review, 43, pp. 1127-1152.

[16] Kaufman, Daniel and Shang-Jin Wei (1999). "Does 'Grease Money' Speed Up the Wheels of Commerce?" NBER Working Paper No. 7093. 
[17] Lipsey, Robert W. (2001). "Foreign Direct Investment and the Operations of Multinational Firms: Concepts, History, and Data," NBER working Paper No. 8665.

[18] Mauro, Paolo (1995). "Corruption and Growth," Quarterly Journal of Economics 110, pp. 681-712.

[19] Markusen, James R. (1995). "The Boundaries of Multinational Firms and the Theory of International Trade," Journal of Economic Perspectives, 9 , pp. 169-189.

[20] Motta, Massimo (1992). "Multinational Firms and the Tariff Jumping Argument: A Game Theoretic Analysis with Some Unconventional Conclusions," European Economic Review 36, pp. 1557-1571.

[21] Reuters News Service, Update-2 "Peugeot Citroen picks Slovakia for new plant," January 15, 2003.

[22] Saggi, Kamal (2002). "Trade, Foreign Direct Investment, and International Technology Transfer: A Survey," World Bank Research Observer, 17(2), pp. 191-235.

[23] Shleifer, Andrei and Robert W. Vishny (1993). "Corruption," Quarterly Journal of Economics," 108(3), pp. 599-617.

[24] Smarzynska, Beata K. and Shang-Jin Wei (2000). "Corruption and Composition of Foreign Direct Investment: Firm Level Evidence," NBER Working Paper No. 7969. 
[25] United Nations Economic Commission of Europe (2001). Economic Survey of Europe 2001:1, Ch. 5, Economic Growth and Foreign Direct Investment in the Transition Economies, Geneva, Switzerland.

[26] Wei, Shang-Jin (2000a). "How Taxing is Corruption on International Investors?" Review of Economics and Statistics, 82(1), pp. 1-11.

[27] Wei, Shang-Jin (2000b). "Local Corruption and Global Capital Flows," Brookings Papers on Economics Activity, 2, pp. 303-346. 